\title{
Investigation of inpatient hyponatraemia in a teaching hospital
}

P. Tzoulis, D. Nair, R. Leyland, E. Woolman, N. Martin, PM Bouloux Centre for Neuroendocrinology, Royal Free Hospital, London, UK

Results

Appropriate investigation of hyponatraemia is essential for optimal management.

The objectives of this study were:

$>$ To evaluate the adequacy of investigation of hyponatraemia.

To assess the effect of factors such as expert input, speciality of caring clinical team and levels of serum sodium on the adequacy of investigation.

\section{Methods}

This retrospective, single-centre study included all inpatients with serum sodium $(\mathrm{sNa}) \leq 128 \mathrm{mmol} / \mathrm{l}$ at any point during hospitalisation over a 3-month period.

Univariate logistic regression models for the association of study groups (medical vs. surgical patients and $\mathrm{sNa}$ $\leq 125 \mathrm{mmol} / \mathrm{l}$ vs. $\mathrm{sNa} 126-128 \mathrm{mmol} / \mathrm{l})$ with the frequency of performance of various investigations enabled computation of RRs (relative risks) .

\begin{tabular}{|ll|}
\hline & \\
\hline Investigations & $\mathbf{N}=\mathbf{1 3 9}(\%)$ \\
\hline Volume status & $86(61.9 \%)$ \\
Serum osmolality & $53(38.1 \%)$ \\
Urine osmolality & $52(37.4 \%)$ \\
Urine Na & $49(35.2 \%)$ \\
Paired osmo $+\mathrm{Na}$ & $44(31.6 \%)$ \\
Serum TFTs & $85(61.1 \%)$ \\
Serum Cortisol & $44(31.6 \%)$ \\
\hline
\end{tabular}

\begin{tabular}{|c|c|c|c|c|}
\hline Investigations & $\begin{array}{l}\text { Nadir sNa } \\
\leq 125 \\
N=87\end{array}$ & $\begin{array}{l}\text { Nadir sNa } \\
126-128 \\
N=52\end{array}$ & $\mathbf{R R}$ & P value \\
\hline Volume status & $73.6 \%$ & $42.3 \%$ & 1.74 & $<0.001$ \\
\hline Serum osmo & $52.9 \%$ & $13.5 \%$ & 4.53 & $<0.001$ \\
\hline Urine osmo & $50.6 \%$ & $15.4 \%$ & 3.28 & $<0.001$ \\
\hline Urine $\mathrm{Na}$ & $47.1 \%$ & $15.4 \%$ & 3.06 & $<0.001$ \\
\hline Paired osmo-Na & $40.2 \%$ & $9.1 \%$ & 4.18 & $<0.001$ \\
\hline Serum TFTs & $70.1 \%$ & $46.2 \%$ & 1.51 & 0.007 \\
\hline Serum cortisol & $45.6 \%$ & $7.7 \%$ & 5.97 & $<0.001$ \\
\hline Endocrine input & $17.2 \%$ & $9.1 \%$ & 1.79 & 0.318 \\
\hline
\end{tabular}

\section{Results}

Among 139 patients (69 males, 70 females) with a mean age $( \pm S D)$ of $70.2 \pm 16.1$ years, 20 patients $(14.4 \%)$ received endocrine input.

$80 \%$ of them underwent complete clinical and laboratory assessment compared to only $5 \%$ of patients managed without endocrine input ( $P$ value $<0.001, R R 15.8,95 \% \mathrm{Cl}$ $7.1-31.1)$.

More patients under medical specialities had appropriate investigations than patients under surgical specialities, but this difference did not reach statistical significance.

\section{Conclusions}

- Hyponatraemia is often underinvestigated, but more cases in this cohort were appropriately investigated than in any previous study.

Endocrine input can improve significantly the adequacy of investigation.

Studies are needed to evaluate if widespread provision of endocrine input by "hyponatraemia teams" can improve patient outcomes. 